\title{
Free Flap Salvage in Lower Extremity Reconstruction via Use of Contralateral Lower Extremity Recipient Vessels
}

\author{
Katelyn G. Bennett, MD ${ }^{1}$ Brian P. Kelley, MD ${ }^{1}$ Theodore A. Kung, MD ${ }^{1} \quad$ Adeyiza O. Momoh, MD ${ }^{1}$ \\ ${ }^{1}$ Section of Plastic Surgery, Department of Surgery, University of \\ Michigan, Ann Arbor, Michigan \\ J Reconstr Microsurg Open 2016;1:117-121.

\begin{abstract}
Address for correspondence Adeyiza O. Momoh, MD, Section of Plastic Surgery, Department of Surgery, University of Michigan, 1500 East Medical Center Drive, 2130 Taubman Center, Ann Arbor, MI 48109
\end{abstract} \\ (e-mail: amomoh@med.umich.edu).
}

\begin{abstract}
Soft-tissue coverage after complex distal lower extremity trauma is often difficult due to limited local flap options and injury to potential recipient vessels when considering microsurgical reconstruction. Therefore, obtaining recipient vessels outside the zone of injury to optimize successful free tissue transfers remains a basic tenet of microsurgery. We present a case of a crush injury to the lower extremity with open tibia and fibula fractures and a large soft-tissue defect that required reconstruction for limb salvage. Due to recipient vessel thrombosis within the affected extremity even well proximal to

Keywords

- cross-leg free flap

- lower extremity reconstruction

- lower extremity trauma the zone of injury, contralateral lower extremity recipient vessels were used as an alternative for cross-leg flap limb salvage. We performed flap pedicle division 6 weeks after inset. Follow-up 9 months after reconstruction showed the patient achieving independent ambulation. In conclusion, cross-leg free flaps may be used as a last resort to successfully salvage flaps in the setting of poor ipsilateral recipient vessels and repeatedly occluding anastomoses.
\end{abstract}

Lower extremity trauma is extremely common and accounts for almost $15 \%$ of emergency room visits, ${ }^{1}$ with 492,000 tibia, fibula, and ankle fractures per year in the United States. ${ }^{2}$ Acute injuries are commonly managed primarily by orthopedic surgeons with fracture fixation or stabilization. In complex fractures involving the lower limb, as in Gustilo grade IIIB or IIIC fractures, limb salvage typically requires the involvement of reconstructive surgeons. Durable soft-tissue reconstruction to support fracture healing and provide coverage of underlying hardware is critical. Often, soft-tissue deficits in the distal third of the leg require free flap reconstruction, as local and regional flaps are unavailable secondary to the extent of the injury or are too small to span the entire defect. ${ }^{3}$

Identification of suitable recipient vessels is challenging when the zone of injury is large. ${ }^{4}$ Similar to pedicled cross-leg flaps, surgeons can consider a free cross-leg flap reconstruction of extremities with an extensive zone of injury and compromise of the regional blood supply. ${ }^{4-6}$ We present a case where a traditional free latissimus dorsi muscle flap reconstruction was

received

August 1, 2016

accepted

August 8, 2016

published online

September 27, 2016 attempted for coverage of a large distal leg defect. However, due to ongoing thrombosis of progressively more proximal vessel anastomoses, the harvested flap was salvaged via the use of the contralateral anterior tibial artery and vein.

\section{Case}

A 24 year-old healthy, non-smoking male presented with a left Gustilo IIIB tibia-fibula fracture secondary to a workrelated forklift crush injury. His initial care at an outside hospital included soft-tissue debridement, fracture external fixation, and wound stabilization with vacuum-assisted closure. He was then transferred 2 days after his initial injury for definitive management. On his assessment at the time of transfer, the distal lower extremity was well perfused and he had intact plantar sensation. His ability to dorsiflex his foot was impaired secondary to loss of his tibialis anterior muscle belly. After further debridement 4 days after his injury, examination revealed a circumferential soft-tissue defect
Copyright $\odot 2016$ by Thieme Medical Publishers, Inc., 333 Seventh Avenue, New York, NY 10001, USA. Tel: +1(212) 584-4662.
License terms

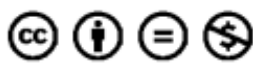

10.1055/s-0036-1593404. ISSN 2377-0813. 
extending from the tibial plateau anteriorly to the proximal dorsal foot. In addition, he had exposed Achilles tendon and approximately $18 \mathrm{~cm}$ of exposed tibia ( - Fig. 1). A computed tomography angiogram revealed patent three-vessel runoff to the foot. He subsequently underwent another debridement involving removal of the external fixator, open reduction internal fixation of the fibula, and tibia fixation with the placement of an antibiotic-eluting intramedullary nail.

The patient initially underwent an ipsilateral chimeric latissimus-serratus free muscle flap reconstruction. Recipient vessel exposure and ipsilateral flap harvest were performed simultaneously (-Fig. 2). The anterior tibial artery was exposed proximal to the open wound and tibia fracture and was deemed to be of good quality with robust bleeding after division. Anastomosis to the left anterior tibial vessels required multiple revisions with successive arterial thrombosis after initially obtaining excellent flow. Eventually, tissue plasminogen activator was infused through the flap, and an alternative recipient vessel at the proximal posterior tibial artery was attempted. Soon after a failed attempt at establishing flow using the posterior tibial vessels, an arteriotomy was made on the flap pedicle, revealing extensive clots within the thoracodorsal artery. At this point, the flap had been ischemic for 7 hours, and a decision was made to end the case.

The patient subsequently returned to the operating room 1 week later for reconstruction with a contralateral latissimus dorsi muscle free flap, with a planned arteriovenous (AV) loop to reach proximal to the zone of injury. In addition, the patient was placed on a heparin drip at the beginning of the case to minimize the risk of intraoperative arterial thrombosis. A reversed saphenous vein graft was harvested from the right lower extremity to be used as an AV loop. An end-to-side hand sewn anastomosis was performed using the tibioperoneal trunk within the popliteal fossa, and an end-to-end anastomosis was performed with a coupler using the more distal posterior tibial vein. Immediately after the anastomoses, flow was established within the loop. The latissimus dorsi muscle flap was then harvested. However, after the flap harvest, the AV loop was found to have no flow. A decision was made to move further proximally, and the arterial end of the vein graft was anastomosed end-to-end to a branch of the popliteal artery with a good size match; the flow was established in the loop and subsequently lost after a period of observation. An end-to-side arterial anastomosis directly into the popliteal artery was then performed and the AV loop was divided at the midpoint along its length. Good pulsatile flow was observed, and an end-to-end anastomosis to the flap thoracodorsal artery was performed. Evidence of flap reperfusion and bleeding were present. However, arterial inflow slowed over the next few minutes and eventually stopped altogether. The anastomosis was taken down, and a host of maneuvers to encourage flow were employed including the application of papaverine to the recipient artery and heparinized saline flushes. Each time, immediate blood flow from the vein graft was robust but would slow and then
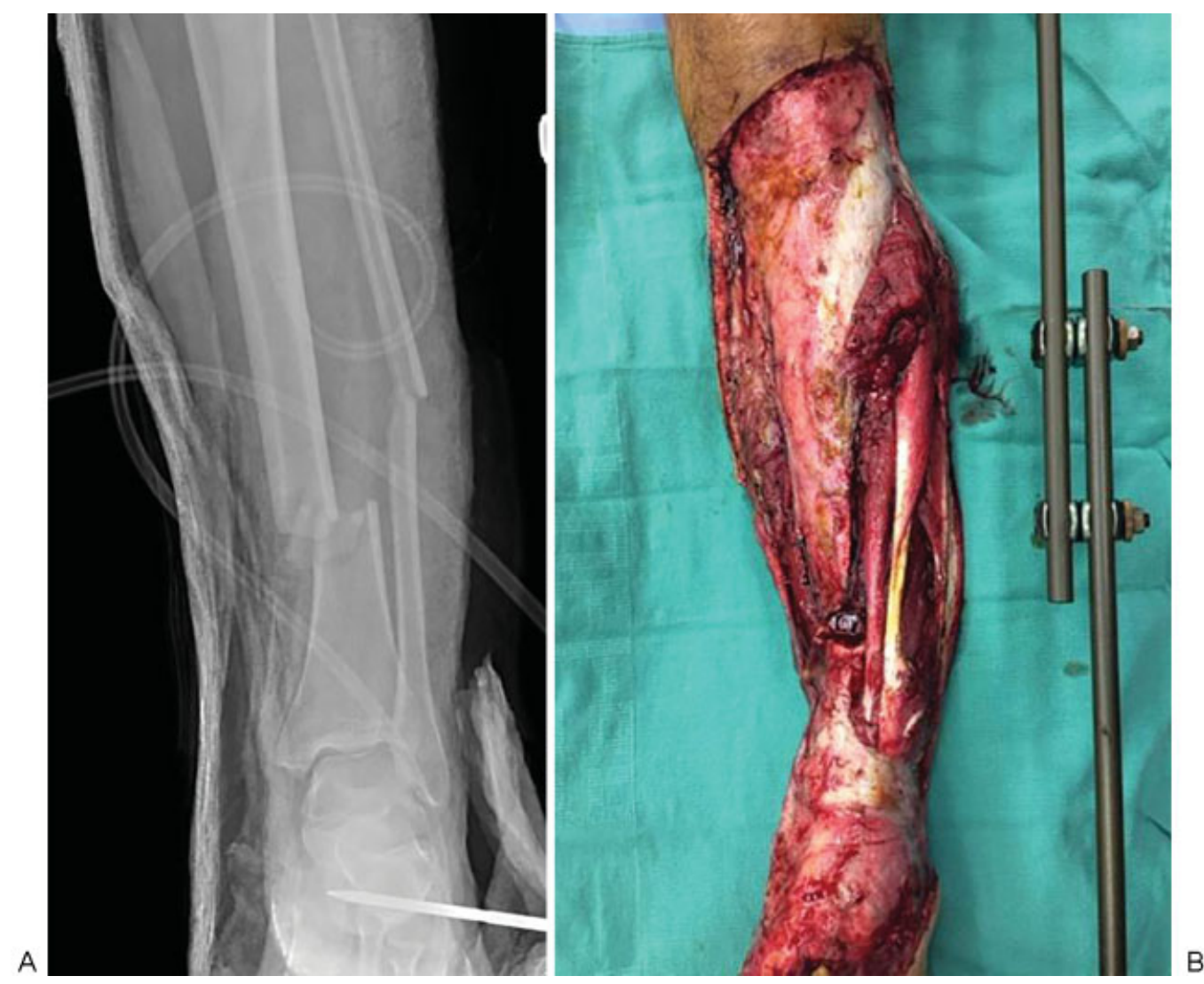

Fig. 1 (A) Radiographic view of the left lower extremity Gustilo IIIB tibia-fibula fractures. (B) Extensive soft-tissue defect following early debridement. 


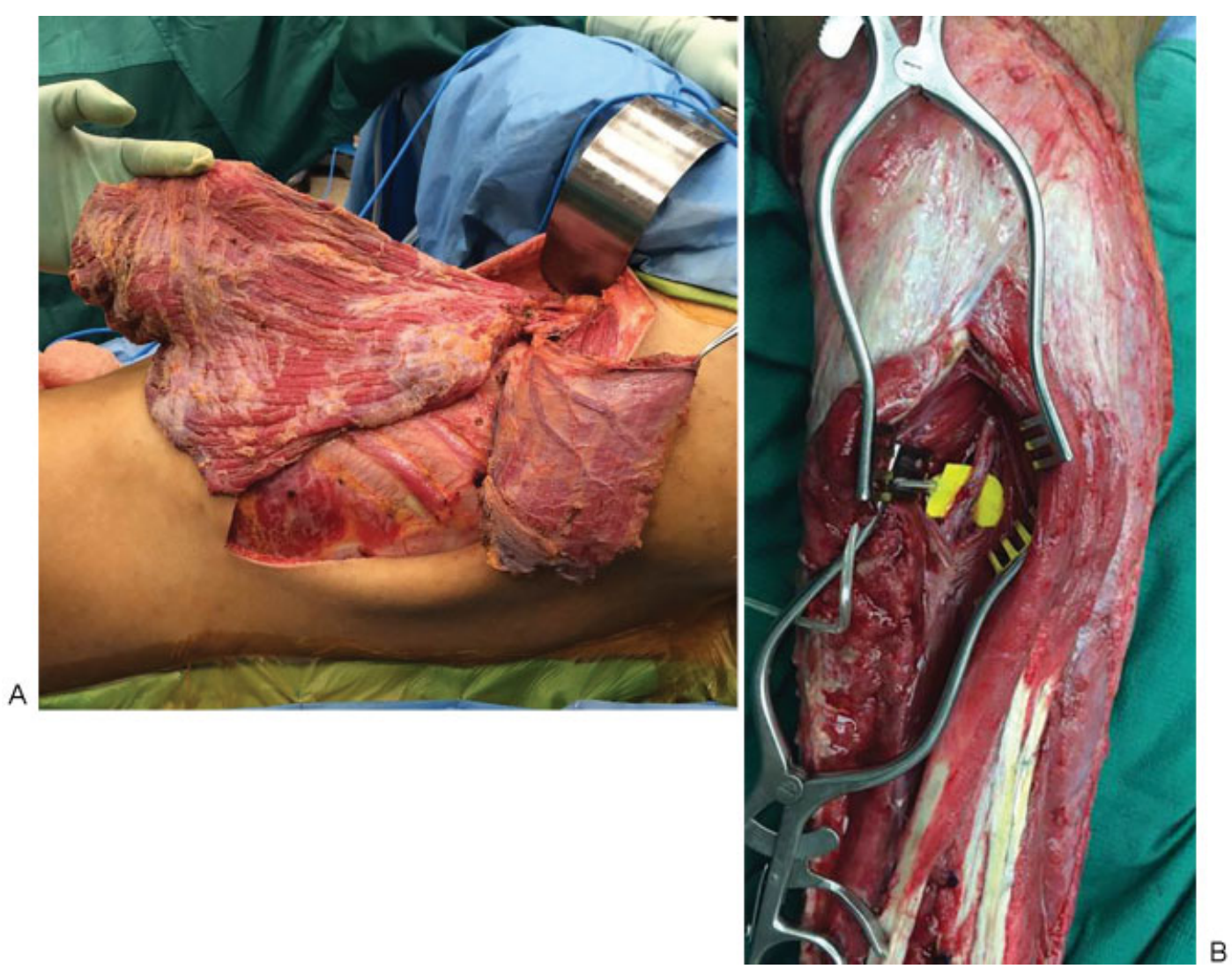

Fig. 2 (A) Harvest of a chimeric Latissimus-Serratus muscle flap and (B) exposure of the anterior tibial vessels in the proximal third of the lower extremity.

eventually stop. Based on this observation, the decision was made to choose an alternative recipient site or to salvage the flap by banking it for later use. Ischemia time at this point had exceeded 5 hours, and there was a concern for potentially losing the flap. It was felt that the extent of the vascular compromise to the left lower extremity vessels was farreaching and not immediately apparent on assessment of the vessel wall adventitia or flow after vessel division. The decision was made to attempt anastomosis on the contralateral anterior tibial vessels (-Fig. 3). These allowed for flow outside the injured limb and still provided flap length for coverage of the contralateral leg defect. The initial inflow was sluggish, but there were clinical signs of flap perfusion. The flap was inset into the left lower extremity defect (-Fig. 4), and a splint was fashioned to prevent separation of the legs.

After several days of close observation and anticoagulation, the flap remained viable (-Fig. 5). The patient returned to the operating room 7 days later for skin grafting of the defect proximal to the flap; complete skin grafting was performed to the muscle flap 3 weeks later. Both extremities were concomitantly put through a dangling protocol after 3 weeks. At 6 weeks postoperatively, laser indocyanine green assessment of flap perfusion was performed with occlusion of flap inflow from the contralateral lower extremity through the use of a contralateral limb tourniquet (Video 1). Once we confirmed adequate perfusion of the flap from the injured recipient limb, the pedicle was divided and the flap inset completed. Inpatient reha- bilitation was performed for a few weeks before discharging the patient home to continue with outpatient rehabilitation. The patient was most recently seen in clinic 9 months after reconstruction (-Fig. 6), at which time he was ambulatory with an ankle-foot orthosis to aid lingering foot drop. He continues to work with physical therapy to improve his mobility.

\section{Video 1}

Intraoperative laser indocyanine green assessment of the cross-leg flap before division of the flap pedicle. With the tourniquet inflated on the contralateral extremity, early inflow in the video is from the ipsilateral extremity (reconstructed extremity) providing confirmation that the cross-leg vascular pedicle can be divided. Online content including video sequences viewable at: www.thieme-connect.com/ ejournals/html/doi/10.1055/s-0036-1593404.

\section{Discussion}

Cross-leg flaps are a proven option in lower extremity reconstruction and were used extensively in World War II for soft-tissue coverage. However, in contemporary practice, these have largely been replaced by microvascular free 


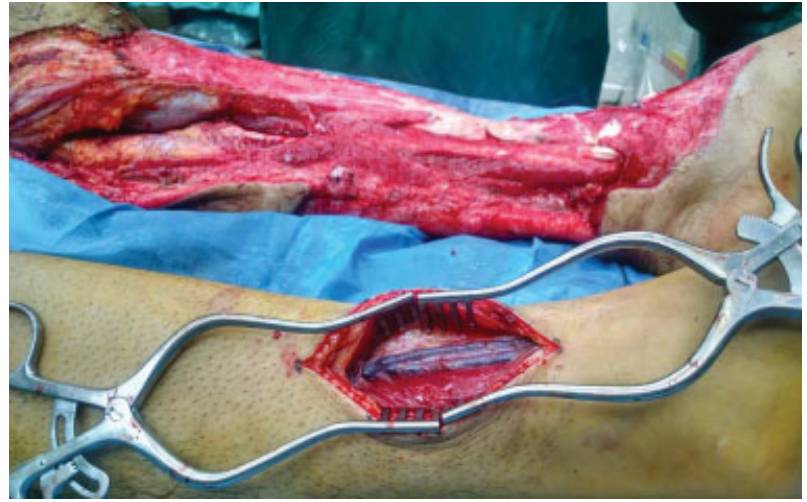

Fig. 3 Exposure of the contralateral anterior tibial vessels in preparation for the anastomosis.

flaps. ${ }^{7,8}$ Interestingly, microsurgeons have revived the concept of utilizing the noninjured contralateral extremity for recipient vessels, designing cross-leg free flaps for patients whose ipsilateral recipient vessels are too damaged for microsurgical anastomosis or for patients whose remaining blood supply to the injured leg is maintained by a single uninjured vessel. ${ }^{4,6,7}$ Anterolateral thigh flaps, ${ }^{9}$ fibula flaps, ${ }^{4}$ latissimus dorsi flaps, ${ }^{6,10}$ scapular flaps, ${ }^{11}$ and rectus flaps ${ }^{12}$ have all been used as cross-leg free flaps. In certain cases, such as ours, it is extremely difficult to find usable ipsilateral vessels that lie outside the zone of injury, thus requiring the surgeon to utilize vessels from the other leg. While the initial presentation of select patients may allow the formation of this operative plan in advance, we had to improvise intraoperatively after multiple failed anastomoses and an extended period of ischemia. In the largest case series to date, there were instances of both elective and salvage cross-leg free flaps. ${ }^{4}$

The initial difficulty in providing a viable reconstruction for this patient may have been the result of trauma-induced hypercoagulability. The patient was young, healthy, and had no documented coagulopathy. However, major trauma is known to create a hypercoagulable state. This can be manifested by increased rates of venous thromboembolism as well as conditions of microthrombosis, such as disseminated intravascular coagulation and systemic inflammatory response syndrome. ${ }^{13}$ Levels of antithrombin, protein

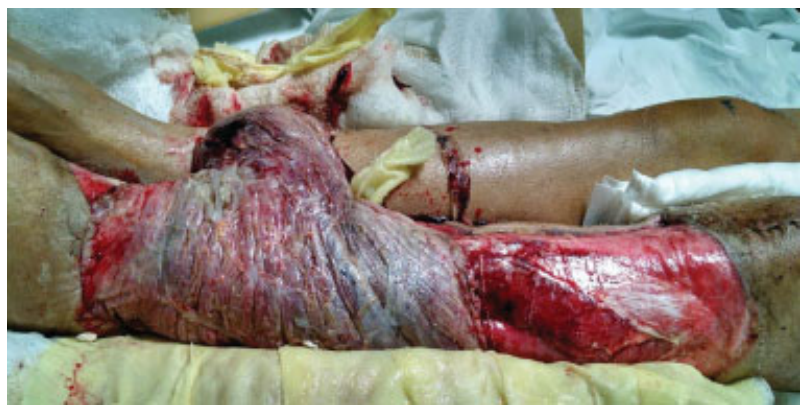

Fig. 5 Flap appearance 1 week postoperatively with grossly viable muscle fibers.

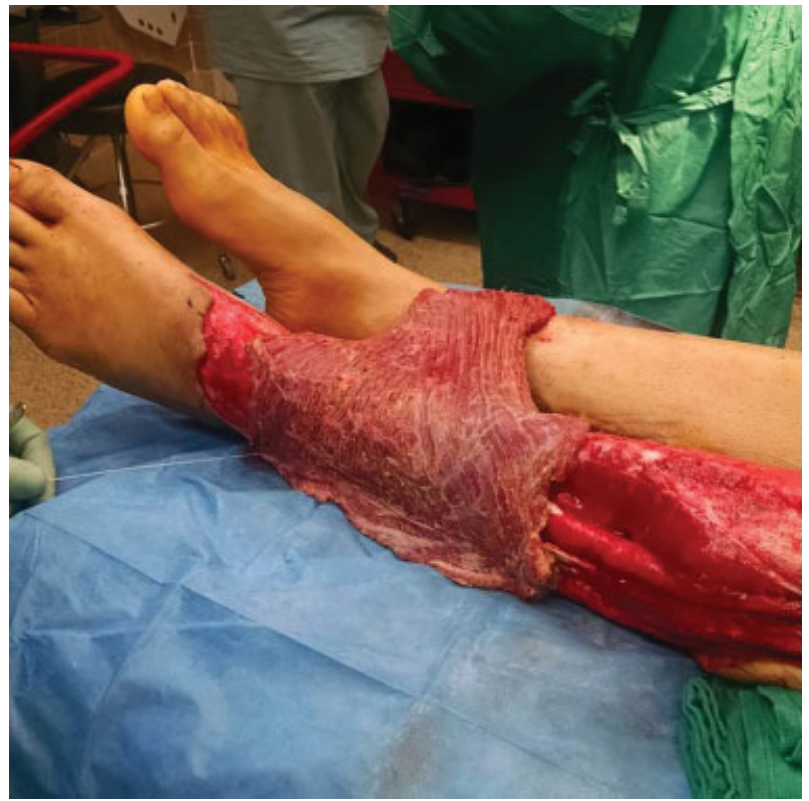

Fig. 4 Cross-leg flap with perfusion established just before inset.

C, and protein S are often decreased in trauma patients, ${ }^{14}$ whereas markers of thrombin generation are increased. ${ }^{15}$ Despite performing all the usual maneuvers to encourage anastomotic patency, including utilization of vein grafts

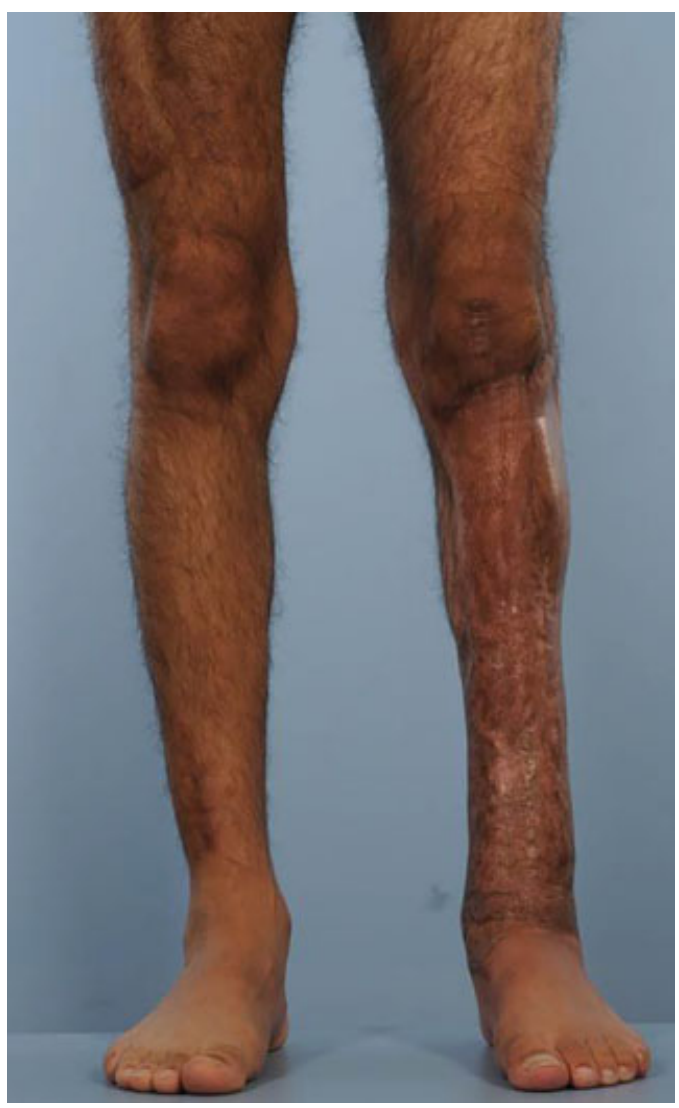

Fig. 6 Follow-up 9 months postoperatively with durable soft-tissue coverage of the reconstructed left lower extremity and a well healed right lower extremity recipient vessel scar. 
and exposing vessels outside of the gross zone of injury, long-term patency could not be established. Even after exposing the contralateral anterior tibial vessels, flow through the pedicle of the cross-leg flap was sluggish. This may suggest a systemic issue rather than isolated thrombosis within the zone of injury or a problem in surgical technique. At this time, no evidence exists to support thrombophilia testing in the acute setting, given that the results will be affected by the underlying trauma state and anticoagulant medications. There are also no current guidelines for management of patients at high risk for microsurgical thrombosis, although both intraoperative and postoperative anticoagulation is suggested. ${ }^{16}$

While successful lower extremity reconstruction with a cross-leg free flap has been demonstrated, it should be considered a secondary option in the microsurgical armamentarium for a variety of reasons. The first is that it involves three different operative sites instead of two. In addition, prolonged immobilization of both lower extremities with casts, splints, or even external fixators ${ }^{4}$ is required to prevent avulsion of the flap from its blood supply. Prolonged immobilization can cause significant joint stiffness; although follow-up by Chen et al revealed a normal range of motion of all joints of the contralateral leg and stiffness consistent with the severity of the trauma in the injured leg. ${ }^{6}$ Immobilized patients are also at an increased risk for deep vein thrombo$\operatorname{sis}^{17}$ and significant muscle atrophy of the contralateral lower extremity.

\section{Conclusion}

The contralateral lower extremity vessels offer a reliable bailout for complicated free tissue transfers to the distal lower extremity, especially when attempts at the use of ipsilateral recipient vessels fail. The value of this option for flap and limb salvage should not be underestimated, as ideal flap options in these patients are in limited supply.

Funding

None.

\section{References}

1 Lambers K, Ootes D, Ring D. Incidence of patients with lower extremity injuries presenting to US emergency departments by anatomic region, disease category, and age. Clin Orthop Relat Res 2012;470(1):284-290

2 Antonova E, Le TK, Burge R, Mershon J. Tibia shaft fractures: costly burden of nonunions. BMC Musculoskelet Disord 2013;14:42

3 Hallock GG. Evidence-based medicine: lower extremity acute trauma. Plast Reconstr Surg 2013;132(6):1733-1741

4 Yu ZJ, Zeng BF, Huang YC, et al. Application of the cross-bridge microvascular anastomosis when no recipient vessels are available for anastomosis: 85 cases. Plast Reconstr Surg 2004;114(5):1099-1107

5 Yu L, Tan J, Cai L, et al. Repair of severe composite tissue defects in the lower leg using two different cross-leg free composite tissue flaps. Ann Plast Surg 2012;68(1):83-87

6 Chen H, El-Gammal TA, Wei F, Chen H, Noordhoff MS, Tang Y. Cross-leg free flaps for difficult cases of leg defects: indications, pitfalls, and long-term results. J Trauma 1997;43(3):486-491

7 Stark RB. The cross-leg flap procedure. Plast Reconstr Surg (1946) 1952;9(3):173-204

8 Agarwal P, Raza H. Cross-leg flap: Its role in limb salvage. Indian J Orthop 2008;42(4):439-443

9 Zhang GL, Chen KM, Zhang JH, Wang SY. Repair of a soft tissue defect of medial malleolus with cross-leg bridge free transfer of anterolateral thigh muscle flap: a case report. Chin J Traumatol 2012;15(5):306-308

10 Kesiktas E, Yavuz M, Gencel E, Dalay C, Acartürk S. Use of cross-leg latissimus dorsi free flap for repair of extensive lower leg electrical injury in a child. Burns 2006;32(4):507-510

11 Hamdi M, Weiler-Mithoff EM, Webster MH. Cross-leg pedicled free scapular flap for neuropathic foot ulcer: case report. J Reconstr Microsurg 2000;16(8):597-601

12 Yamada A, Harii K, Ueda K, Asato H, Tanaka H. Versatility of a cross-leg free rectus abdominis flap for leg reconstruction under difficult and unfavorable conditions. Plast Reconstr Surg 1995;95(7):1253-1257

13 Selby R, Geerts W, Ofosu FA, et al. Hypercoagulability after trauma: hemostatic changes and relationship to venous thromboembolism. Thromb Res 2009;124(3):281-287

14 Owings JT, Bagley M, Gosselin R, Romac D, Disbrow E. Effect of critical injury on plasma antithrombin activity: low antithrombin levels are associated with thromboembolic complications. J Trauma 1996;41(3):396-405, discussion 405-406

15 Dries DJ. Activation of the clotting system and complement after trauma. New Horiz 1996;4(2):276-288

16 Pannucci CJ, Kovach SJ, Cuker A. Microsurgery and the Hypercoagulable State: A Hematologist's Perspective. Plast Reconstr Surg 2015;136(4):545e-552e

17 Toker S, Hak DJ, Morgan SJ. Deep vein thrombosis prophylaxis in trauma patients. Thrombosis 2011;2011:505373 